\title{
Mistrust and social hierarchies as blind spots of ICT4D projects
}

\author{
Lessons from Togo and Rwanda
}

\author{
Roos Keja, Department of Social and Cultural Anthropology, Goethe-Universität Frankfurt am Main, \\ Norbert-Wollheim-Platz 1, 60323 Frankfurt am Main (rooskeja@gmail.com) \\ Kathrin Knodel, Collaborative Research Centre "Discourses of Weakness and Resource Regimes", \\ Goethe-Universität Frankfurt am Main (kknodel@em.uni-frankfurt.de)
}

Information and communication technologies for development (ICT4D) are seen to have great potential for boosting democratization processes all over the world by giving people access to information and thereby empowering them to demand more accountability and transparency of authorities. Based on ethnographic research in Togo and Rwanda on an SMS-based citizen monitoring and evaluation system, this article argues that focusing on access to information is too narrow a view. We show that it is crucial to take into account the respective socio-political backgrounds, such as levels of mistrust or existing social hierarchies. In this context, mobile phone usage has rather varied and ambiguous meanings here. These dynamics can pose a challenge to the successful implementation of ICT4D projects aimed at political empowerment. By addressing these often overlooked issues, we offer explanations for the gap between ICT4D assumptions and people's lifeworlds in Togo and Rwanda.

\section{Misstrauen und soziale Hierarchien als blinde Flecken in ICT4D-Projekten \\ Erkenntnisse aus Togo und Ruanda}

Im Bereich Informations- und Kommunikationstechnologie für Entwicklung (ICT4D) wird großes Potenzial gesehen, um weltweit Demokratisierungsprozesse voranzutreiben, indem die Menschen Zugang zu Informationen erhalten und dadurch befähigt werden, von ihren Regierungen mehr Rechenschaft und Transparenz einzufordern. Auf der Grundlage ethnographischer Untersuchungen in Togo und Ruanda zu einem SMS-basierten Bürgerbeobachtungs- und -bewertungssystem wird argumentiert, dass eine Fokussierung auf den Zugang zu Informationen zu eng ist. Wir zeigen, dass es wichtig ist, den sozio-politischen Hintergrund, wie etwa das Maß an Misstrauen und bestehende soziale Hierarchien, zu berücksichtigen. Diese Dynamiken können eine Herausforderung für die erfolgreiche Implementierung von ICT4D-Projekten mit dem Ziel der politischen Teilhabe darstellen. Die Einbeziehung

This is an article distributed under the terms of the Creative Commons Attribution License CCBY 4.0 (https://creativecommons.org/licenses/by/4.0/)

https://doi.org/10.14512/tatup.28.2.s35

Submitted: 15. 03.2019. Peer reviewed. Accepted: 06.05.2019 dieser oft übersehenen Aspekte ermöglicht es, die Diskrepanz zwischen den Annahmen und Zielen von ICT4D und der Lebenswelt der Menschen in Togo und Ruanda besser zu verstehen.

Keywords: mistrust, social hierarchies, ICT4D, Togo, Rwanda

\section{Introduction}

Soon after the introduction and spread of the mobile phone throughout the world, which was unexpectedly rapid throughout Africa (de Bruijn et al. 2009; Etzo and Collender 2010), there was much optimism about its transformative force for development of the so-called 'Global South' among entrepreneurs, development practitioners and scientists alike. Optimists hailed the potential for economic development and democratisation, a flourishing telecommunication market, increased opportunities to maintain and broaden social networks, and, very importantly, better access to information (Donner 2006; Southwood 2008). The mobile phone has proven to be a highly accessible means of communication, and is the main device for accessing the internet in Africa (Sey 2011). The field of information and communication technologies for development (ICT4D) benefits enormously from this boom and is currently intertwined in many different areas, such as e-health, e-agriculture, digital economy, as well as civic engagement and political empowerment - the area from where our own research experience arises.

One of the basic assumptions within the dominant development discourse within this latter area is that new ICT have a great potential for boosting democratisation processes all over the world, giving people access to information and thereby empowering them to demand more accountability and transparency of authorities, i. e. executive powers of the state (Bimber 2000; Bratton 2013; Hayes and Westrup 2012; Ochara and Mawela 2015). However, in light of repressive political contexts in Africa and beyond, political empowerment and democratisation 
are highly problematic ideas. Moreover, mobile phone usage and perceptions appear to be rather ambiguous (de Bruijn et al. 2009; Hahn 2012; Wasserman 2011). Our own research in Togo and Rwanda revealed that, in order to get a better insight into people's possibilities to access and use information, it is crucial to take the respective socio-political background into account. Two aspects were striking and will be discussed in detail here: the reigning mistrust and the existing social hierarchies.

In both countries, the mistrust vis-à-vis local and national authorities is widespread, albeit embedded within different historical and social settings. The same can be said for social relations; it has even proven to be dangerous to trust one's own neighbour. In Rwanda, the genocide in 1994 killed over 800,000 people, which created an atmosphere of mistrust still prevalent today, as neighbours and friends were caused to kill each other. In Togo, where one family has reigned since 1967, popular discontent is 'silenced' in many ways; from intimidations and bribery to outright violence and incarceration. Our interlocutors often looked at getting a detailed picture of people's perceptions and usage of mobile phones on the one hand, and their general relations and communication with local authorities on the other hand. We strived for a balanced representation of society, but it is important to note a slight tendency towards younger and male persons.

\section{ICT4D and access to information}

The field of ICT4D, at the intersection of practice and theory, has received much scholarly attention. Some authors embraced the boom as a major opportunity for development (CharlesIyoha 2010; Donner 2006; Southwood 2008), whereas several others soon started to question this 'revolution' or 'leapfrogging development', taking a more critical stance (Alzouma 2005; de Bruijn et al. 2009; Etzo and Collender 2010; Hahn 2012; Mudhai et al. 2009). Expectations of the transformative potential of ICT for processes of democratisation, as well as their repercus-

\section{Access to information alone is not decisive for people's (civic) behaviour.}

over their shoulder, lowering their voices when discussing politically sensitive subjects. Concerning the second aspect of social hierarchies, our data suggests that, whereas mobile phones do offer new pathways for information exchange, this mainly happens within existing social networks. Thus, mobile phones facilitate horizontal communication, but not automatically vertical communication. Our argument in this article is that - contrary to the dominant assumption underlying many ICT4D projects - access to information alone is not decisive for people's (civic) behaviour. What is more decisive is the way in which people assess both this information and their course of action - up until now often blind spots in the design and implementation of ICT4D projects. This article is a contribution to close the gap between this ICT4D imaginary and people's lifeworlds (Jackson 2017).

The data on which this article is based was collected between 2015 and 2018 during a total of two months of ethnographic fieldwork in Rwanda in different urban and rural areas, and a total of six months in Togo in mostly urban areas. Our research took place in the framework of a development project that aimed at implementing an SMS-based citizen monitoring and evaluation system. We participated in project meetings and relied both on informal conversations while 'hanging out' and participant observations that where conducted in close contact with local research assistants. Additionally, about 110 in-depth interviews were conducted in Rwanda, and about 200 in-depth interviews, 100 mobile communication logs and 10 focus groups were conducted in Togo. Even though the empirical data from Togo is more voluminous, the comparison with Rwanda is valuable, adding depth to the discussion. The data collection aimed sions, have been analysed in various ways; mobile phones can boost citizen journalism and facilitate instant information sharing, hence boosting democratisation, but can at the same time also lead to new strategies for authoritative regimes to control information exchange (Kleine and Unwin 2009; Mutsvairo and Harris 2016).

Research projects that focus on the appropriation or 'domestication' of mobile phones show that mobile phone usage and perceptions are much more ambiguous than the positive imaginary of several large ICT4D projects (Horst and Miller 2006; Hahn and Kibora 2008). Such approaches allow for taking into account the influence of existing mistrust and social hierarchies, and the ways in which people relate to 'the political' in their everyday lives. This permits a more comprehensive image of the exchange of information in which mobile communication can be placed.

As a starting point for our argument, we want to note that even if people have access to what could be called 'public' information, they do not necessarily perceive this information as being trustworthy (Keja 2019). This stems from the complex intertwinements between social and political mistrust, both in Togo and Rwanda, which play an important role in all communication processes. Our data reveal that, in communication processes, people often try to keep their intentions to themselves and try to calculate other people's intentions, which leads to indirect and encoded ways of communication. This can be seen as part of people's strategies to cope with and make sense of their social environment. Therefore, in these areas, information itself can be characterised by its instability and unreliability. In the 
discussion about access to information, the perception of information as being untrustworthy is often lacking, whereas it has a large impact on the successful implementation and durability of ICT4D projects that aim at boosting democratisation. An important element in people's evaluation of trustworthiness of information lies within the relationship between the sender and the receiver of the information.

\section{Mobile phones and hierarchies: "We don't skip a level"}

The first nuance that we want to bring to the fore in this article is an aspect which is all too often overlooked by ICT4D projects, or simply categorised as a 'cultural issue' to be resolved locally: the aspect of social hierarchies and power differences. This aspect, which also has some economic implications, will reveal the existence of horizontal and vertical communication that structure and determine mobile phone usage.

In the politically constrained contexts we studied, people do not believe in the anonymity of mobile communication. Especially ICT4D projects that aim for digital civic engagement should take this concern into account. As will be discussed in more detail below, in a context in which the right of expression is under pressure, these concerns are not merely theoretical. In general, people prefer face-to-face discussions about important subjects, which is not only driven by issues of anonymity, but also simply because of the high costs of telecommunication. The persons who are considered to be wealthier (superiors, chiefs, etc.), are expected to be the ones carrying most of the costs of mobile communication.

Taking an ever closer look at people's mobile communication behaviour, it becomes evident that it largely depends on their position in society and on their networks. As also noted elsewhere, the mobile phone is mostly used for "micro-coordination" (Ling

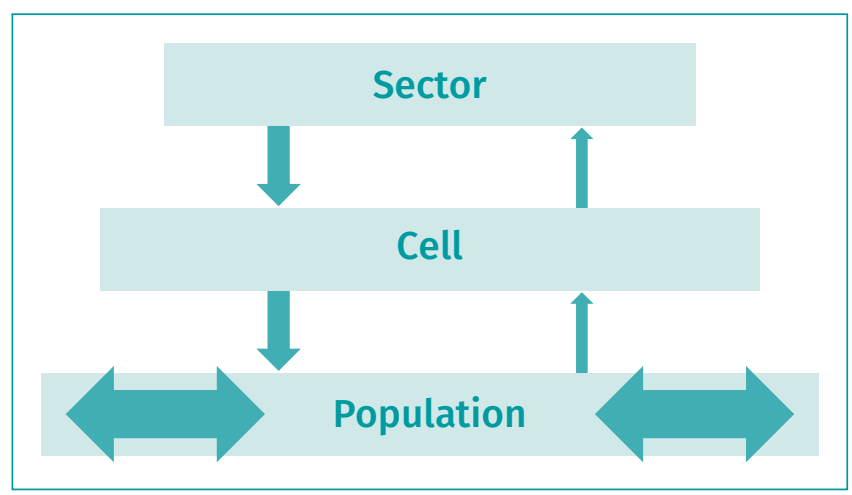

Fig. 1: Horizontal and vertical communication across hierarchies.

Source: authors' own compilation

$g u d u^{1}$ or municipality, and it is not recommended to go directly to the next higher administrative level (i. e. the cell), let alone the sector, district or provincial level. In Togo, the image seems to be bleaker; in case they have a problem that affects the community, people may turn to the customary chief in their area, as the municipal councils suffer from a lack of legitimacy, and the prefecture is often a bridge too far for the population and has a mandate on a different level. The general image of the municipality is that "they are thieves" and hardly anything good is expected to come from those authorities.

In Rwanda, contact with a higher authority only takes place after consultation with the leader of the umudugudu. If the competences and responsibilities of this level are exceeded, as in some cases of inheritance, land or community-led categorisation, the local leader forwards the advice seeker to the next higher level. Even though the hierarchies discussed above are far more complex than we can spell out here, these settings can be summarised in the Rwandan expression "We don't skip a level" (Fig. 1). Skipping the lower level would be considered as indirect

\title{
Social hierarchies and power differences structure
}

\author{
and determine mobile phone usage, leading to horizontal \\ and vertical communication.
}

and Yttri 2002, p. 139), as a prelude to face-to-face encounters. People mostly communicate with their beloved ones and peers, and when it concerns professional relations, they can call their direct superiors. However, it is not common to directly call someone in a higher position. Even if someone knows the number of the chief or mayor, they would usually only reach these persons through an intermediary.

Both in Rwanda and Togo, people seem to be strongly locally oriented in their communication and problem-solving. In Rwanda, most problems are addressed at the level of the umudu- criticism of that level, which is absolutely not anchored in people's habits. As a result, most people never have contact with the cell or higher levels, whose responsibilities are often unknown. Likewise, most people are not familiar with internal communication processes among the authorities. This lack of information also feeds the idea that they are not in the position to request certain information from the authorities, which is, at the same time,

1 Meaning village, or small settlement in Kinyarwanda. It represents the smallest administrative unit. 
a challenge and an opportunity for increasing their transparency and accountability.

This leads us to conclude that a differentiation has to be made between horizontal and vertical communication. People use mobile phones to communicate with their peers on the same hierarchical level in order to meet or organise something, or exchange information. Horizontal communication does not create barriers, but the situation is different for vertical communication. Top-down communication to inform citizens about meetings or activities is common, but people are not comfortable with the idea of calling 'upwards', which is strongly related to people's general socio-economic and educational background, and to socio-political conditions.

\section{Understanding mistrust:} "Everyone is lying"

Albeit in very different ways, both Togo and Rwanda have a recent past of social, political and economic instability, and everyday life has been politicised to such an extent that information exchange is often affected by concerns about direct repression or other negative consequences. Until today Togo's population has lived under a repressive regime since 1967, in which the only power change was from father to son, whereas Rwanda has greatly suffered from a civil war that started in 1990, leading to a genocide that took place in 1994, which is still the reason for an atmosphere of mistrust throughout society. In our conversations, we noticed that people avoid discussing subjects related to politics, and, in Rwanda, this is particularly sensitive in relation to ethnicity. Under these politically constrained condi-
Rwanda has provided new possibilities for connectivity, in several domains we also notice a deepening of the already existing levels of mistrust. At first glance, our interviewees emphasised the many advantages of mobile communication: first and foremost, the new possibilities of getting informed about the well-being of one's beloved ones, followed by the diminished need for travelling in order to transfer a message, a means to get information about a petty job or a business opportunity and a means to resolve emergencies. In certain ways, the mobile phone carries the promise of a way out of hardship (Ligtvoet 2018). Some of our interviewees emphasised only the advantages of the mobile phone. However, some interviewees stated that it also increases the social pressure of responding to certain requests. The mobile phone not only brings more freedom and new ways to escape others, but also new possibilities to control others.

Along the same line, most people point to the possibility of betraying others with the help of a mobile phone, exemplified by the exclamation "the phone has turned all of us into liars", expressed by people from different layers of society in Togo. Especially with regard to couples, but also between parents and children, the mobile phone has an impact on the precarious balance between freedom and control. It is broadly acknowledged that the phone can lead to break-up and divorce, as not only dating has become easier for men and women, but also finding proof for extramarital relations when scrolling through the phone of one's partner (Archambault 2009; Kenaw 2012). This indicates that the mobile phone has contributed to an increasing mistrust within intimate relationships. In addition, both in Togo and Rwanda, practically all of our interlocutors can recall a story in which they or their acquaintances were called by scammers and were betrayed.

\section{The mobile phone has contributed to an increasing mistrust, as some say: "the phone has turned all of us into liars".}

tions, people have an interest in practising self-censorship and, at times, misrepresenting information, as was evident in our interviews and observations.

In such an environment, one's own neighbours and even one's most intimate contacts cannot be trusted. Besides political or ethnic differences, spiritual reasons were also mentioned for keeping one's intentions to oneself. For instance in Togo, our interlocutors take care with whom to share their travel plans, or plans for the future, as they want to avoid that someone's jealousy may be aroused, which may then lead to encountering 'bad luck' on their road. These common assumptions justify referring to mistrust as an organising principle of society, which is interlinked with trust, but can be considered as being more than its mere antithesis, as expounded by Carey (2017).

Although the introduction of the mobile phone in such constrained and codified communication landscapes as in Togo and
As SIM cards are registered by name, people have concerns about matters of anonymity; not only vis-à-vis the telecommunication operators, but also the authorities. The largest operators are often equated with the government, and in both countries, people assume that their mobile communication can be easily wiretapped by state actors. In Rwanda, it has been relatively easy to retrieve the ID data on which a phone number is registered by entering a certain USSD code, which then provides information about the age, gender and district of the owner. For many reasons, people in possession of a phone do not want others to access such data. Finally, during periods of increased socio-political unrest, as has been the case in Togo in the second half of 2017 , possessing a mobile phone can be outright dangerous; several people were jailed after encountering elements of the security forces which found 'evidence' in their phone's photo gallery or WhatsApp images. Among others aroused by the opposition, 
people massively replied to a call for a nationwide manifestation in August 2017 to demand political reforms. Soon, protesters were met with tear gas and clashes between protesters and security forces even led to several deaths between August and October 2017. Even though we are convinced that the manifestations would have never had such massive response without the mobilising force of WhatsApp, the violent reaction of the security forces has emphasised once again that revolution takes more than a mobile phone (Mutsvairo and Harris 2016).

\section{Conclusions}

From what has been presented above on people's everyday encounters and perceptions of mobile phones, it has become clear that the mobile phone can bring new forms of control and of escaping control, not only on the interpersonal level, but also on communal and municipal levels. The phone has certainly increased the intensity of information exchange, but this does not seem to contribute to more transparency. On the contrary, it seems to lead to new ways of concealing and revealing information. We argue that the mobile phone under conditions as in Rwanda and Togo instead increases mistrust within relationships, which has consequences for assessing ICT4D projects. As we have shown, the trustworthiness of information knows a high level of instability within these contexts, which seems to be based upon fragile social fabrics. From this data, it can be derived that the point of departure of ICT4D should be reconsidered, as increased access to information does not simply lead to more transparency and accountability on behalf of the authorities. From a worst case scenario perspective, if the mobile phone changes anything at all, it makes political leaders more aware of the destabilising force of new media, and instigate them to diversify their strategies of repression.

As a point of departure, we have argued for shifting the focus from technologies as such to the people who make use of these technologies. We emphasised the potential risk of what we called blind spots in the planning and implementation of ICT4D projects that might hinder or reduce their success. From our data and experience, a deeper understanding in particular of the importance of social hierarchies and mistrust for the content of information exchange is necessary for embedding any ICT4D project in a certain local context. Projects should be designed more sensitively towards power relations from the design phase onwards. We argue for a much more participatory approach in the design process of ICT4D projects so that they can be carefully constructed within the lifeworlds of the users of new technologies, as to increase the chances of durability.

These complex local constellations, in which power differences and widespread mistrust are key issues to be taken into account, demand flexibility on behalf of ICT4D practitioners and projects. Finally, as mobile communication is always embedded in local communication structures, there should be a continuous focus on creating synergies with existing channels of communication. For ICT4D projects, which are often linked to local development, it is worth gaining better insight into such communication flows. By following the flows of connectivity between different online and offline media, such as community meetings, radio shows, Facebook pages and WhatsApp groups, ICT4D projects can centralise people who make use of these technologies. In this way, their beneficiaries can then profit more from the vast range of opportunities offered by these technologies.

\section{Acknowledgements}

The authors gratefully acknowledge funding from the Federal Ministry for Economic Cooperation and Development (BMZ) within the scope of the Programme d'Appui à la Décentralisation (Togo) and the Programme for Support to Decentralisation (Rwanda), implemented in cooperation with the German Development Bank (KFW). The findings, interpretations and conclusions expressed here are entirely those of the authors, and do not necessarily represent the views of BMZ or KfW.

\section{References}

Alzouma, Gado (2005): Myths of digital technology in Africa. Leapfrogging development? In: Global Media and Communication 1 (3), pp.339-356.

Archambault, Julie (2009): Being cool or being good. Researching mobile phones in Mozambique. In: Anthropology Matters 11 (2). Available online at https://www.anthropologymatters.com/index.php/anth_matters/article/ view/161/287, last accessed on 22.04.2019.

Bimber, Bruce (2000): The study of information technology and civic engagement. In: Political Communication 17, pp. 329-333.

Bratton, Michael (2013): Briefing. Citizens and cell phones in Africa. In: African Affairs 112 (447), pp. 304-319.

Carey, Matthew (2017): Mistrust. An ethnographic theory. Chicago: HAU Books. Charles-Iyoha, Christiana (2010): Mobile telephony. Closing the gap. In: Sokari Ekine (ed.): SMS uprising. Mobile phone activism in Africa. London: Fahamu Press, pp. 116-123.

de Bruijn, Mirjam; Nyamnjoh, Francis; Brinkman, Inge (eds.) (2009): Mobile phones. The new talking drums of everyday Africa. Bamenda: Langaa Group.

Donner, Jonathan (2006): The use of mobile phones by microentrepreneurs in Kigali, Rwanda. Changes to social and business networks. In: Information Technologies and International Development 3 (2), pp. 3-19.

Etzo, Sebastiana; Collender, Guy (2010): The mobile phone 'revolution' in Africa. Rhetoric or reality? In: African Affairs 109 (437), pp. 659-668.

Hahn, Hans (2012): Mobile phones and the transformation of society. Talking about criminality and the ambivalent perception of new ICT in Burkina Faso. In: African Identities 10 (2), pp. 181-192.

Hahn, Hans; Kibora, Ludovic (2008): The domestication of the mobile phone. Oral society and new ICT in Burkina Faso. In: Journal of Modern African Studies 46 (1), pp. 87-109.

Hayes, Niall; Westrup, Chris (2012): Context and the processes of ICT for development. In: Information and Organization 22 (1), pp. 23-36.

Horst, Heather; Miller, Daniel (2006): The cell phone. An anthropology of communication. Oxford and New York: Berg Publishers.

Jackson, Michael (2017): How lifeworlds work. Emotionality, sociality, and the ambiguity of being. Chicago: The University of Chicago Press. 
Keja, Roos (2019): Intimate information flows in hardship. Mobile phones and the civic-ness of connectivity in Sokodé, Togo. Unpublished PhD dissertation, Goethe University Frankfurt.

Kenaw, Setargew (2012): Cultural translation of mobile telephones. Mediation of strained communication among Ethiopian married couples. In: The Journal of Modern African Studies 50 (1), pp. 131-155.

Kleine, Dorothea; Unwin, Tim (2009): Technological revolution, evolution and new dependencies. What's new about ICT4D? In: Third World Quarterly 30 (5), pp. 1045-1067.

Ligtvoet, Inge (2018): Made in Nigeria. Understanding duress and upwardly mobile youth in the biography of a young entrepreneur in Enugu. In: Conflict and Society. Advances in Research 4 (1), pp. 275-287.

Ling, Rich; Yttri, Birgitte (2002): Hyper-coordination via mobile phones in Norway. In: James Katz and Mark Aakhus (eds.): Perpetual contact. Mobile communication, private talk, public performance. Cambridge: Cambridge University Press, pp. 139-169.

Mudhai, Okoth; Tettey, Wisdom; Banda, Fackson (eds.) (2009): African media and the digital public sphere. New York: Palgrave Macmillan.

Mutsvairo, Bruce; Harris, Suzanne (2016): Rethinking mobile media tactics in protests. A comparative case study of Hong Kong and Malawi. In: Ran Wei (ed.): Mobile media, political participation, and civic activism in Asia. Dordrecht: Springer, pp. 215-231.

Ochara, Nixon; Mawela, Tendani (2015): Enabling social sustainability of e-participation through mobile technology. In: Information Technology for Development 21 (2), pp. 205-228.

Sey, Araba (2011): 'We use it different, different'. Making sense of trends in mobile phone use in Ghana. In: New Media \& Society, 13 (3), pp. 375-390.

Southwood, Russell (2008): Less walk, more talk. How Celtel and the mobile phone changed Africa. Chichester: John Wiley and Sons.

Wasserman, Herman (2011): Popular media, democracy and development in Africa. London: Routledge.

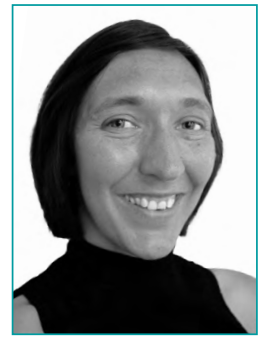

DR. DES. ROOS KEJA

defended her doctoral thesis about mobile phones and the civic-ness of connectivity in Sokodé, Togo at the Department of Social and Cultural Anthropology at Goethe University Frankfurt in 2019. She is also involved in MOWAD community projects stimulating participation and inclusion of African migrants in the Netherlands.

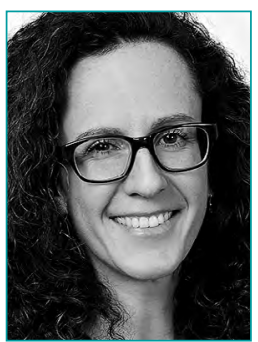

\section{DR.DES. KATHRIN KNODEL}

is a social and cultural anthropologist by training and has been a Postdoctoral Research Fellow at the CRC 1095 'Discourses of Weakness and Resource Regimes' at Goethe University Frankfurt since 2015. Within this project, her research mainly focusses on local NGO actors in Burkina Faso, their working worlds, and lifeworlds.

\section{GAIA liasters Student Paper Award}

The international journal GAIA - Ecological Perspectives for Science and Society invites liasters students to participate in the 2020 GAIA liasters Student Paper Award.

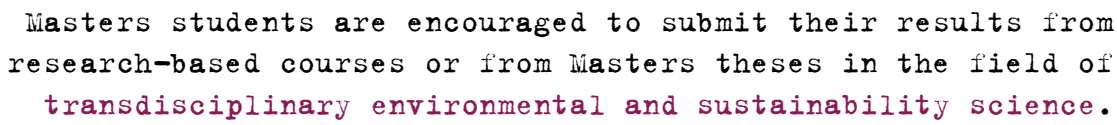

\section{Submission guidelines and more information:}

ww.oekom.de/zeitschriften/gaia/student-paper-award Deadine for submission: November 4, 2019.

The winner will be selected by an international jury and will be granted a prize money of EUR 1,500 endowed by the Selbach Umwelt Stiftung and Dialogik gGmbH, as well as a free one-year subscription to GAIA, including free online access. The winner may also be invited to submit his or her paper for publication in GAIA. 